\title{
Fosil Kaynak Tüketiminin Karbon Ayak İzine Etkisi: Türkiye’den Kanıtlar
}

\author{
Hakan YILDIZ ${ }^{1 *}$ A. Yusuf YÜKSEL ${ }^{2}$, Ümit ÖZDEMIR \\ ${ }^{1}$ Harran Üniversitesi, Bozova Meslek Yüksekokulu, Çevre Teknolojileri Bölümü, Sanlıurfa, Türkive \\ ${ }^{2}$ Harran Üniversitesi, Ziraat Fakültesi, Zootekni Bölümü, Sanlıurfa, Türkiye \\ ${ }^{2}$ Munzur Üniversitesi, Tunceli Meslek Yüksekokulu, Yönetim ve Organizasyon Bölümü, Tunceli, Türkiye
}

Geliş/Received: 20. 01.2021

Kabul/Accepted: 17.09 .2021

Yayın/Puplished: 31.12.2021

Atıf yapmak için: Yıldız, H., Yüksel, Y.A. \& Özdemir, Ü. (2021). Fosil Kaynak Tüketiminin Karbon Ayak İzine Etkisi: Türkiye’den Kanıtlar. Anadolu Çev. ve Hay. Dergisi, 6(4), 467-474.

How to cite: Yıldız, H., Yüksel, Y.A. \& Özdemir, Ü. (2021). The İmpact of the Fossil Resource Consumption on the Carbon Footprint: Evidence from Turkey. J. Anatolian Env. and Anim. Sciences, 6(4), 467-474.

iD : https://orcid.org/0000-0002-2181-7226

D : https://orcid.org/0000-0003-0670-6664

iD: https://orcid.org/0000-0001-7045-9608

*Sorumlu yazarın:

Hakan YILDIZ

Harran Üniversitesi, Bozova Meslek

Yüksekokulu, Çevre Teknolojileri Bölümü,

Şanlıurfa, Türkiye

凶: hyildiz@harran.edu.tr
Öz: Küresel iklim değişikliği, son yıllarda yaşanan sağlık ve çevre krizlerinin en önemli nedenidir. Hizla artan enerji talebinin, yüksek oranda fosil kaynak tüketiminden (FKT) karşılanması bu problemin ana kaynağıdır. Türkiye karbon ayak izi (KAİ) verilerindeki artış bu tüketimin en önemli göstergesidir. Bu çalışmada 1971-2017 dönemi, KAİ verileri ve FKT arasındaki ilişki Johansen eşbütünleşme analizi ile incelenmiştir. Yapılan test istatistiklerinin sonuçlarına göre iki değişken arasında uzun dönemli bir ilişkinin olduğu görülmüştür. Aynı zamanda bu ilişkinin kısa dönemde etkilerini görmek için hata düzeltme modeli uygulanmış ve test sonucunda hata düzeltme değeri de anlamlı çıkmıștır. Böylelikle iki değișken arasında uzun dönemli ilişkinin tutarlı olduğu belirlenmiştir. Ayrıca eşbütünleşme testinin sınaması yapılmış bulunan sonuçlar ile iki değiş̧en arasında kurulan eşbütünleşmenin doğru olduğu tespit edilmiştir. Sonuç olarak FKT'nin, KAİ'de neden olduğu artış istatistiksel olarak da anlamlı bulunmuştur.

Anahtar kelimeler: Fosil kaynak tüketimi, iklim değisikliği, johansen eşü̈tünlesme testi, karbon ayak izi.

\section{The İmpact of the Fossil Resource Consumption on the Carbon Footprint: Evidence from Turkey}

*Corresponding author's:

Hakan YILDIZ

Harran University, Bozova Vocational

School, Department of Environmental

Technologies, Sanliurfa, Turkey

凶: hyildiz@ harran.edu.tr

\begin{abstract}
Global climate change is the most important reason for the health and the environmental crises which are experienced in recent years. The main source of this problem is that the rapidly increasing energy demand is supplied by consumption highly of fossil resources (FRC). The increase of the data on Turkey carbon footprint (CF) is the most significant indicator for this consumption. In this study, the relationship between CF data and FRC for the period of 1971-2017 was examined by the Johansen cointegration analysis. According to these results of the test statistics, it was seen that there was a long-term relationship between the two variables. At the same time, the error correction model was applied to view in the short-term effects of this relationship, and the error correction value was discovered to be meaningful at the end of the test. Thus, it was determined that the long-term relationship between the two variables was consistent. Besides, the cointegration test was examined then, it was achieved that the cointegration between its result and the two variables were correct. As a result, the increase of the $\mathrm{CF}$ is caused by the consumption of the FRC was discovered to be statistically meaningful.
\end{abstract}

Keywords: Carbon footprint, climate change, fossil resource consumption, Johansen cointegration test.

\section{GíRIS}

Birleşmiş Milletler (BM) raporunda ilk kez yer alan sürdürülebilir kalkınma kavramı 'Doğanın ve gelecek kuşakların kendi gereksinimlerine cevap verme yeteneklerini tehlikeye atmadan, günlük ihtiyaçlarımızı temin etmek ve kalkınmak.' olarak tanımlanmıştır. Raporda ayrıca sürdürülebilir kalkınmaya ulaşmada en önemli 
unsurun enerji olduğu belirtilmiştir (UN, 1987). Enerji kaynakları, insan toplumunun hayatta kalması ve gelişmesi için kritik öneme sahiptir (Qin vd., 2020). Teknolojik gelişmeler, nüfus artışı ve insan yaşam standartlarında meydana gelen değişiklikler nedeniyle enerjiye olan talep her geçen gün artmaktadır. 2040 yılına kadar küresel enerji tüketiminin \% 48 artacağı ve bu tüketimin \% 78'nin fosil yakıtlar tarafından karşılanacağı tahmin edilmektedir (Paramati vd., 2017). Fosil yakıtlar, gelişmiş ve gelişmekte olan ülkelerin hem enerji üretim sistemlerinin hem de ulaşım sistemlerinin temelini oluşturmaktadır (Martins vd., 2018). Fosil kaynak tüketiminde (FKT) meydana gelen artış; enerjiye ulaşım sıkıntısı, küresel enerji fiyatlarında dalgalanma ve karbon salınımı gibi olumsuz etkileri de beraberinde getirmiştir. Hükümetler arası İklim Değiş̧ikliği Paneli (IPCC) raporuna göre küresel sera gazı emisyonlarının yaklaşık \% 65'nin FKT'den kaynaklandığını göstermektedir (IPCC, 2014). Son yıllarda yapılan geniş kapsamlı çalışma sonuçlarına göre dünyanın sürdürülebilir kalkınmasına yönelik en büyük tehdit artan sera gazı emisyonlarından kaynaklanan kötüleşen çevre kalitesidir (Khan vd., 2021). İklim değişikliği sosyoekonomik sistemlerin işleyişi, insan sağlığ 1 ve refahı üzerinde önemli zararlı etkilere sahip olan, fiziksel çevrede veya biyotada meydana gelen, büyük küresel bir tehdittir (IPCC, 2019; UN, 1992). Ayrıca IPCC'nin yayınladığı bir raporda iklim değişikliği ile mücadelede acil ekonomik ve politik değiş̧ikler olmadıkça, dünya üzerinde birçok doğal güzelliğin yok olacağı, ciddi oranda yetersiz beslenme, açlık ve gıda kıtlığının ortaya çıkacağı vurgulamıştır (IPCC, 2019).

Küresel tehdit haline gelen bu problemin etkilerini azaltmak için, BM 'Dünyamızı dönüştürmek: 2030 Sürdürülebilir Kalkınma Gündemi' başlıklı raporunda sürdürülebilir kalkınma hedefleri (SKH) kapsamında ekonomik, çevre ve sosyal konuları içeren 17 hedef belirlemiștir (UN, 2015). Bu hedeflerden biri de iklim değişikliği ve etkileriyle mücadele için acil önlem alınmasıdır (Salvia vd., 2019). Cevre kalitesi üzerine olumsuz etkisi olan iklim değişikliği ve küresel ısınma ile ilgili politikaların uygulanmasında en önemli faktör ve kaynaklardan biri ekolojik ayak izi (EAI) verileridir (Monserrate, 2020). EAİ, bir nüfusun yaşam biçimi ve tüketim modeli ile tüketilen doğal kaynakların aralarındaki ilişkileri belirlemek için kullanılır (Rees, 1992). EAİ, çevresel bozulmayı ölçmek için altı ana değişkeni (karbon, tarım arazisi, orman, otlak, balıkçılık ve yapılanmış alan ayak izi) hesaba katar (Qayyum vd., 2021).

EAİ verilerinde en etkin bileşen karbon ayak izidir (KAİ). KAİ, Küresel ölçekte ve Türkiye'nin toplam ayak izindeki payı en büyük olan, aynı zamanda en hızlı artış gösteren ayak izi bileşenidir (WWF, 2012).
Bu çalı̧̧manın amacı, Türkiye'de FKT'nin çevre kalitesi ve insan sağlığ üzerine etkilerini tespit etmektir. Çalışmada öncelikli olarak FKT'nin çevre kalitesi ve insan sağlığ1 üzerine etkileri kısa bir literatür özeti ile anlatılacaktır. Sonraki aşamda ise 1971-2017 dönemi FKT verileri ile Türkiye KAİ verileri arasındaki ilişki istatistiksel olarak Johansen eşbütünleşme testi ile sınanacak ve sonuçlar değerlendirilecektir.

Fosil Kaynak Tüketiminin İnsan Sağglı̆ğ ve Çevre Kalitesine Etkisi: 2018'de 7,4 milyar olan dünya nüfusunun, 2050'de 9,7 milyar ve 2100 yılında 10,8 milyar olması tahmin edilmektedir (UN, 2019). Yaşayan sistemler, devamlılıklarını sürdürmek için enerjiye ihtiyaç duyarlar. Canlı sistemler için gerekli olan enerji oranı ve türü, bu sistemlerin boyutu ve karmaşıklı̆g arttıkça artar (Lidicker, 2020). Hizla artan nüfus yüksek enerji talebini de beraberinde getirmiştir.

Enerji, modern teknoloji çağında, yalnızca ekonomik büyümenin değil, aynı zamanda bir ülke için temel stratejik rezervdir (Rauf vd., 2020). Sanayi devriminden sonra endüstrileşmenin hızla yayıldığ 1 dünyada enerji, temel girdi olmuştur (Kowalski vd., 2019). Gelişen teknoloji, enerji tüketim modelleri, enerji politikası ve iş sektörlerinde değişen öncelikler, enerji sektöründe büyük bir dönüşüme işaret etmekle beraber, önümüzdeki 40 yılın geçmişten farklı olacağını gösteriyor (Kober vd., 2020). Son yıllarda dünya geneli enerji tüketimindeki ciddi artış bunu desteklemektedir. 2018 yılında dünya toplam enerji tüketimi $\% 2,2$ büyüme oranıyla 9937 Mtep (milyon ton petrol enerjisi) olarak rapor edilmiştir. Ayrıca 1990-2018 yılları arasında dünyada, kaynağına göre enerji arzı verilerine göre en yüksek payı sırasıyla petrol, kömür, doğalgaz, biyoyakıtlar ve atık, nükleer, hidroelektrik ve rüzgâr-güneş enerjileri takip etmiştir (IEA, 2020). Birincil enerji kaynağı (gıda, yem ve yakacak odun) olarak biyokütleye dayalı bir tarımsal enerji rejiminden fosil yakıt bazlı bir rejime geçiş, sanayi devriminin kilit unsurlarından biridir (Kowalski vd., 2019).

Fosil yakitlar, hidrokarbon ve yüksek oranlarda karbon içeren kömür, petrol ve doğal gaz gibi doğal enerji kaynaklarıdır (Bilim ve Teknik, 2016). Fosil yakıtların kullanımına bağlı olarak hem yerel hem de küresel ölçekte ekosistem bozulması, son yıllarda net olarak belgelenmiştir (Petrov vd., 2017). Fosil kaynakların kullanılması sonucu atmosfere verilen $\mathrm{CO}_{2}$ çevre kalitesi üzerine olumsuz etkisi olan sera gazı emisyonlarının 2/3'lük kısmını oluşturmaktadır. Sera gazları, atmosferin kızılötesi radyasyonu emen ve yeniden yayan hem doğal hem de antropojenik gaz bileşenlerini (\% 36-70 Su buharı, \% 9-26 Karbon dioksit, \% 4-9 Metan, \% 3-7 Ozon) ifade eder (UN, 1992). Atmosferde en çok biriken sera gazı olan $\mathrm{CO}_{2}$ küresel çevre sorunlarından biri olan iklim değişikliğinin 
yanı sıra okyanusların asitlenmesi gibi diğer ekolojik sorunlara da sebep olmaktadır (WWF, 2012).

İklim değişikliği, fosil yakıt tüketimi, arazi kullanım değişiklikleri, ormansızlaştırma ve sanayi süreçleri sonucunda atmosfere salınan sera gazındaki hızlı artışı, doğal sera etkisini kuvvetlendirmesi ile yerkürenin ortalama yüzey sıcaklığındaki artışı ve iklimde meydana gelen değişiklikleri ifade etmektedir (MGM, 2017).

İklim değişikliği, tarım, ormancılık, deniz ve okyanus yaşamı, biyoçeşitlilik, enerji, su kaynakları, hava kalitesi, ekonomi, insan sağlığı, ülkeler arası çatışma gibi birçok alanda ciddi problemlere sebep olmaktadır (Cai vd., 2020). Birçok bilim adamı iklim değişikliğinin neden olduğu sorunlar hakkında çalışmalar yapmıştır. Örneğin iklim değişikliğinin, ekosistem ve biyoçeşitlilik (Sintayehu vd., 2020), hava kalitesi (Coelho vd., 2020), üretim tesisleri (Arbex \& Batu, 2020), balık ve balıkçılık (Koomson vd., 2020), atıksu artıma tesisleri (Hughes, 2020) ve tarımsal üretim (Buono, 2021) gibi farklı birçok alanda etkilerinin araştırıldığı çalışmalar mevcuttur.

Özellikle son yıllarda yapılan bazı çalışmaların ortak sonucu, iklim değişikliğinin, insan yaşamını ve sağlığını çeşitli şekillerde etkilediğidir. (Haines \& Ebi, 2019; Nicholas vd., 2020). İklim değişikliği kaynakli; aşırı sıcaklıkların ölüm ve hastalık oranı üzerinde doğrudan veya dolaylı etkileri, ultraviyole 1şııım, sel, kuraklık gibi mekanizmaları insan sağlığını etkilemektedir (Haines vd., 2005). Örneğin sel felaketi yaşanan bir bölgede insanların ruh sağliklarının bozulduğu tespit edilmiştir (Hrabok vd., 2020). Başka bir çalışmada aşırı sıcaklık ve ultraviyole ışınıma maruz kalan bireylerin deri ve cilt sağlıklarının son yıllarda daha da fazla olduğu tespit edilmiştir (Schachtel vd., 2020). Daha farklı bir çalışmada ise iklim değişikliğinin neden olduğu sebepler kapsamında, insanlarda akciğer kanserinin iklimsel değişiklik ile nedenselliği araştırılmıştır (Hiatt \& Beyeler, 2020).

Dünya sağlık örgütünün verilerine göre yılda yedi milyondan fazla insan -dünyadaki ölüm sayısının 1/8'ine denk gelmekte- hava kirliliğinden ölmektedir. $\mathrm{Bu}$ ölümlerin \% 90'1, fosil kaynakların tüketilmesinden oluşan, iklim değişikliğine bağlı dış ortam kalitesinin, sınır değerin altında olmasından kaynaklanmaktadır. Ayrıca iklim değişikliğinin 2030 ile 2050 yılları arasında yetersiz beslenme, sitma, ishal ve sıcak stresi nedeniyle diğer ölümlere ek yılda yaklaşık 250,000 insanın ölümüne neden olması beklenmektedir.

Türkiye'de Mevcut Durum: Bir önceki y1la göre \% 1,39'luk bir artış hızı ile 2019 yılında Türkiye nüfusu 83 milyon olmuştur. Türkiye hızla gelişen bir ülke ve enerjiye olan ihtiyacı da hızla artmaktadır (Özgül vd., 2020). Türkiye'nin enerji politikası, artan nüfusun taleplerini karşılama, enerji ithalatı ve çevresel zararların azaltılmasına yönelik sürekli olarak gelişmektedir (IEA, 2016).

Küresel enerji talebinde yaşanan artş̧a benzer şekilde 2018 yılında Türkiye nihai enerji tüketim miktarı bir önceki yıla göre 1,9 artı̧̧ ile 105 mtep olmuştur (IEA, 2020a). Ayrıca 1990-2018 yılları arasında Türkiye'de kaynağına göre enerji arzı tüm Dünyada olduğu gibi fosil ve yenilenemeyen enerji kaynaklarından sağlanmıştır (IEA, 2020b). Türkiye sera gazı emisyonları 2018 yılında bir önceki ylla göre \% 0,5 azalarak 20,9 milyon ton (Mt) $\mathrm{CO}_{2}$ eşdeğer (eşd.) olarak hesaplanmıştır (Şekil 1). Emisyonlarda en yüksek payı \% 71,6 ile enerji kaynaklı emisyonlar alırken bunu sirasıly \% 12,5 ile endüstriyel işlemler ve ürün kullanımı, \% 12,5 ile tarımsal faaliyetler ve $\% 3,4$ ile atık takip etmiştir. (TUIK, 2020).

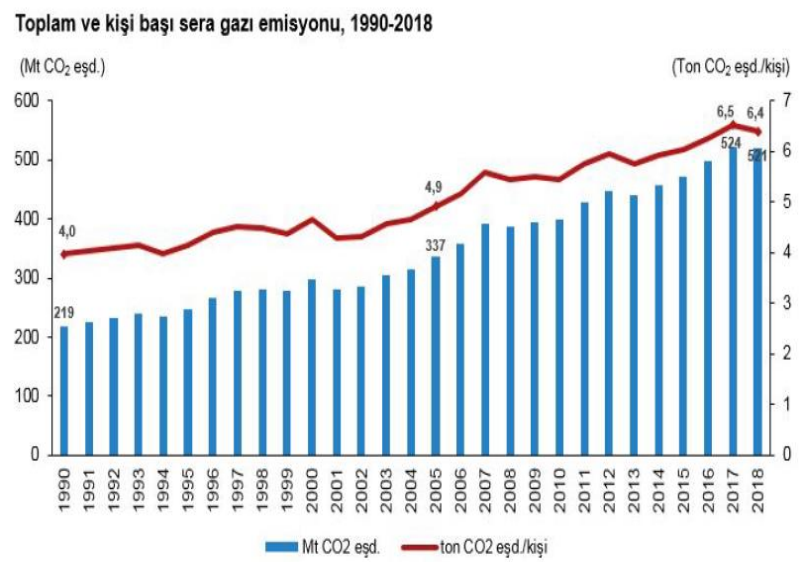

Şekil 1. 1990-2018 Y1lları Türkiye $\mathrm{CO}_{2}$ Emisyonları (TUiK, 2020).

Figure 1. $\mathrm{CO}_{2}$ Emissions 1990-2018 Year of Turkey.

Sera gazı emisyonlarının çevre kalitesindeki etkilerini, EAİ tüketim verileri ile daha net olarak görmekteyiz. EAİ tüketim verileri, mevcut teknoloji ve kaynak yönetimiyle bir bireyin veya topluluğun tükettiği kaynakları üretmek ve oluşturduğu atığı bertaraf etmek için gerekli olan ve biyolojik açıdan verimli toprak ve su alanıdır "küresel hektar" (kha) ile ifade edilir (WWF, 2012). 1961-2017 yılları arasında Türkiye'nin EAİ verilerine göre 1961 yılında kişi başı EAİ tüketimi 1,56 kha iken, 2017'de yaklaşık olarak \% 56 civarında gerçekleşen bir artış ile bu rakam 3,51 kha olmuştur (GFP, 2020a). EAİ hesaplamalarının yapılmasında arazi türlerine göre, karbon, tarım arazisi, orman, otlak, yapılaşmış alan ve balıkçılık sahası ayak izi olarak altı ayrı kategoride incelenmiştir (Şekil 2).

1961-2017 yılları arasında Türkiye EAİ verilerinde en fazla artış KAİ'nde olmuştur. 2017 yılında KAİ \% 64'lük (kişi başı 2,23 kha) orana ulaşmıştır. Onu sırasıyla tarım, orman, otlak, balıkçılık sahası ve yapılanmış alan ayak izleri takip etmiştir. 
KAİ verisi kişi başı atmosfere salınan $\mathrm{CO}_{2}{ }^{\prime} \mathrm{yi}$ tutmak için gerekli arazi anlamına gelmektedir (Jóhannesson vd., 2020). Ayak İzi hesaplarında en yüksek emilimi sağlayan arazi türü olan orman alanı cinsinden hesaplanır (WWF, 2012). Türkiye'de EAİ bileşenlerinden KAİ veri sonuçlarında meydana gelen bu artış, küresel ölçekte olduğu gibi, Türkiye'de de sürdürülebilir olmayan bir yaşam biçiminin işaretidir (WWF, 2012).

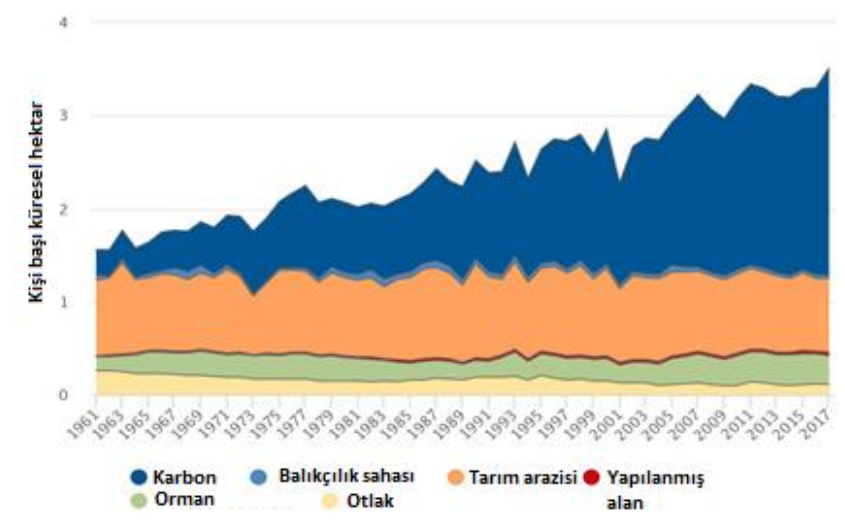

Şekil 2.Türkiye EAİ bileşenleri (GFP, 2020b)

Figure 1. Turkey EF components

İlk bölümde kapsamlı olarak ele alınan yüksek enerji talebininin fosil kaynaklardan sağlanması tüm dünyada olduğu gibi Türkiye'de de ciddi problemlere sebep olmaktadır.

\section{MATERYAL VE METOT}

Veri ve Model: Bu çalı̧̧mamızda, KAİ (Şekil 3) ile FKT (Şekil 4) verileri arasındaki ilişki, 1971-2017 dönemini içeren veri seti kullanılarak Türkiye kapsamında incelenmiştir. Bağımsız değişken için FKT (ton eş değer petrol enerjisi) ve bağımlı değişken KAİ (kişi başı küresel hektar) verileri kullanılmıştır (Tablo 1).

Tablo 1. Bağımlı ve Bağımsız Değişken Verileri.

Table 1. Dependent and Independent Variable Data.

\begin{tabular}{lcl}
\hline Değişkenler & \multicolumn{1}{c}{ Açıklama } & \multicolumn{1}{c}{ Kaynak } \\
\hline Karbon Ayak İzi & Kişi Başı Tüketimin Karbon & Küresel Ayak İzi \\
(KAİ) & Ayak İzi (kha) & Ağı (GFP) \\
Fosil Kaynak & Türkiye Toplam Fosil Kaynak & Uluslararası Enerji \\
Tüketimi (FKT) & Kullanımı (tep) & Ajansı (İEA) \\
\hline
\end{tabular}

$\mathrm{Bu}$ çalışma kapsamında özellikle zaman serileri arasındaki uzun dönem ilişkinin belirlenmesi için literatürde oldukça yaygın kullanılan Johansen eşbütünleşme testi uygulanacaktır. Öncelikli olarak test için kullanacağımız değişkenlerimizin zaman serisi özellikleri incelenmiştir. Çünkü zaman serisi özelliklerinin incelenmemesi durumunda, iki değişken için yapılacak her türlü tahminin gerçekte var olmayan ilişkilerini, varmış gibi göstererek sahte regresyon sorununa neden olacaktır (Çiftci, 2014). Bu amaçla serilerin durağanlığ edilecektir.

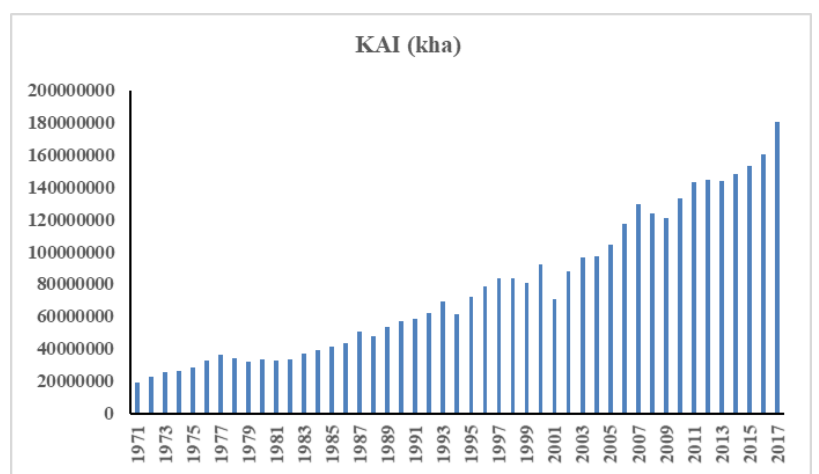

Şekil 3. 1971-2017 KAİ verileri (Kişi başı küresel hektar) (GFP, 2020b).

Figure 3. Data CF 1971-2017 (Global hectares per capita)

\section{FKT (Tep)}

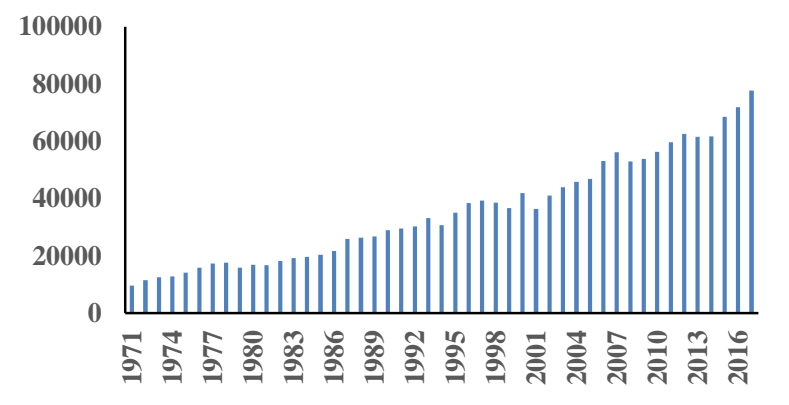

Şekil 4. 1971-2017 FKT verileri (Ton eş değer petrol enerjisi) (IEA, 2020b).

Figure 4. 1971-2017 FRC data (Tonne equivalent petroleum energy).

Eğer bir serinin zaman içerisinde ortalaması, varyansı ve kovaryansı değişmiyorsa bu seriye durağan zaman serisi denmektedir. Durağan olmama durumu ise bunun tersidir. Çalışmada değişkenlerin durağanlık derecelerinin belirlenmesi amacıyla birim kök testleri uygulanmıştır. Bu aşamada öncelikli olarak geleneksel birim kök testlerinden olan Genişletilmiş Dicky-Fuller (ADF) testi ve Phillips-Peron (PP) testleri uygulanacaktır (Dicky \& Fuller, 1997; Phillips \& Perron, 1988). Dickey ve Fuller'a göre hata teriminin ortalamasının sıfır, sabit bir varyansa, normal dağılıma ve otokorelasyon içermeyen bir yapıya sahip olduğu kabul edilmektedir. Hata teriminin ortalamasının normal dağılmadığı durumlar için Dickey ve Fuller, otokorelasyonu gidermek için bağımlı değişkene ait gecikme değerlerini dahil ederek Genişletilmiş Dickey Fuller (ADF) testini önermişlerdir (Akel, 2015). PhillipsPerron (PP) birim kök testi ise ADF birim kök testinin tamamlayıcısı niteliğindedir. PP birim kök testi, ADF ile kıyasalandığında daha esnek varsayımlara sahiptir (Çiftci, 2014).

Yapısal kırılma, regresyon parametrelerinde zaman içinde ani bir değişikliği ifade etmektedir. Geleneksel birim kök testleri, bu yapısal kırılmaları gözden kaçırır. Bu nedenle değişkenlere yapısal kırılmaları dikkate alan birim kök testide uygulanacaktır. 
Zaman serilerinin aralarındaki eş bütünleşme ilişkisini belirlemek için yaygın olarak kullanılan birden fazla yöntem vardır (Engle \& Granger, 1987; Johansen, 1988; Johansen \& Juselius, 1990). Bu testlerden biri olan Johansen eşbütünleşme testi, ençok olabilirlik tahmin yöntemini kullanarak eşbütünleşik vektörlerin varlığını test etmeye yönelik geliştirilmiş bir eşbütünleşme analizidir (Akel, 2015).

$\mathrm{Bu}$ yönteme göre değişkenler arasında tespit edilen eşbütünleşme ilişkisi, gerçek uzun dönemli bir ilişki anlamına gelmekte ve değişkenlerin uzun dönem birlikte hareket ettiğini göstermektedir. Johansen'a göre eşbütünleşme analizinin yapılabilmesi için bütün seriler aynı düzeyde -I(1)- durağan olmalıdır. Johansen eşbütünleşme testi değişkenler arasındaki tüm koentegre vektörlerin tahminine izin verdiği için oldukça güvenilir bir testtir. Bu çalışmamızda değişkenler arasında ilişki için Johansen eşbütünleşme uygulaması kullanılmıştır. Ayrıca eşbütünleşme testleri sonucunda uzun dönem eşbütünleşmesi tespiti yapılan iki serinin kısa dönem dinamiklerini araştırmak amacıyla vektör hata düzeltme modeli de VECM tahmin edilecektir (Çiftci, 2014).

Vektör hata düzeltme modeliyle değişkenler arasında ortaya koyduğumuz uzun dönemli eşbütünleşme sonuçlarının kısa dönemde de anlamlı bulunması halinde kurulan eşbütünleşmenin model artıklarının otokorelasyona ve değişen varyans problemine sahip olmaması gerekmektedir (Kocabıyık, 2016). Bu nedenle eşbütünleşme modelinin sınaması yapılarak doğruluğu test edilecektir.

\section{BULGULAR VE TARTIŞMA}

Birim Kök Testi Uygulaması: Yapılan geleneksel ve yapısal kırılmalı birim kök test sonuçlarına göre KAİ ve FKT değişkenlerin her ikisinin de seviyede I(0) değil, farkta I(1) durağan olduğu görülmüștür (Tablo 2). Her iki değişkenin I(1) çıkması ile aralarında uzun dönemli bir ilişkinin belirlenmesinde Johansen eşbütünleşme testinin uygulanması uygun olmuştur (Tablo 3).

Johansen Eşbütünleşme Test Uygulamast: Test uygulamasına geçmeden önce serilerin gecikme değerlerinin doğru girilmiş olması gerekmektedir. Çünkü analiz gecikme uzunluğuna duyarlıdır (Kocabıyık, 2016). Kullanılan analiz programında bu menüyü kullanarak değişkenler için uygun VAR modeli ve gecikme uzunlukları tespit edilmiştir (Tablo 4).

Uygulanan gecikme uzunluğu test sonuçlarına göre tüm kriterlere göre 1 gecikmeli model uygun bulunmuştur. Bundan sonraki aşamada eşbütünleşme testi yapilacaktır. (Tablo 5).

Tablo 5, incelendiğinde hesaplanan İz (Trace) istatik ve Maksimum Öz Değer test (Maximum
Eigenvalue) istatik sonuçlarının kritik değerden büyük olması \%5 anlamlılık düzeyinde modelde iki koentegrasyon vektörünün bulunduğunu göstermektedir. Dolayısıyla Johansen eşbütünleşme testiyle elde edilen sonuçlara bakarak KAİ ve FKT değişkelerinin uzun dönemde birbirlerini etkilediğini söylemek mümkündür.

Tablo 2. Birim Kök Testleri.

Table 2. Unit Root Tests.

\begin{tabular}{|c|c|c|c|c|}
\hline \multirow[t]{2}{*}{ Phillips-Peron (PP) } & Seviyede I (0 & & & Birinci Fark I (1) \\
\hline & KAİ & FKT & & $\begin{array}{ll}\mathrm{d}(\mathrm{KAI}) & \mathrm{d}(\mathrm{FKT})\end{array}$ \\
\hline \multirow[t]{2}{*}{ Sabitli } & t-İstatistik 0,9752 & 4,3659 & t-İstatistik & $-9,6103-7,5035$ \\
\hline & Olasılık 0,9956 & 0,9999 & Olasılik & $0,0000^{* * * *} 0,0000^{* * *}$ \\
\hline \multirow[t]{2}{*}{ Sabitli ve Trendli } & t-İstatistik $-2,8530$ & $-0,4417$ & t-İstatistik & $-10,8199-10,0653$ \\
\hline & Olasılık 0,1868 & 0,9828 & Olasılık & $0.0000^{* * * *} 0.0000^{* * * *}$ \\
\hline \multirow[t]{2}{*}{ Sabit ve Trend olmadan } & t-İstatistik 5,0327 & 10,0621 & t-İstatistik & $-7,6914-5,5838$ \\
\hline & Olasılık $\quad 0,9999$ & 0,9999 & Olasılık & $0,0000^{* * *} 0,0000^{* * *}$ \\
\hline \multicolumn{4}{|c|}{$\begin{array}{ll}\text { Artırılmıs Dickey-Fuller (ADF) } & \text { Seviyede I (0) } \\
\end{array}$} & Birinci Fark I (1) \\
\hline & KAİ & FKT & & $\mathrm{d}(\mathrm{KAI}) \quad \mathrm{d}(\mathrm{FKT})$ \\
\hline \multirow[t]{2}{*}{ Sabitli } & t-İstatistik 0,4870 & 1,5370 & t-İstatistik & $-8,8328-7,4499$ \\
\hline & Olasilık $\quad 0,9844$ & 0,9992 & Olasılık & $0,0000^{* * * *} 0,0000^{* * *}$ \\
\hline \multirow[t]{2}{*}{ Sabitli ve Trendli } & t-İstatistik -3,0197 & $-1,0848$ & -Istatistik & $-8,8720-8,0514$ \\
\hline & Olasilık 0,1381 & 0,9206 & Olasılık & $0,0000^{* * * *} 0,0000^{* * * *}$ \\
\hline \multirow[t]{2}{*}{ Sabit ve Trend olmadan } & t-İstatistik 2,8986 & 4,4790 & t-İstatistik & $-7,7110-5,4338$ \\
\hline & Olasılık $\quad 0,9988$ & 0,9999 & Olasılık & $0,0000^{* * *} 0,0000^{* * *}$ \\
\hline
\end{tabular}

Tablo 3.Yapısal Kırılmalı Birim Kök Testleri.

Table 3. Structural Break Unit Root Tests.

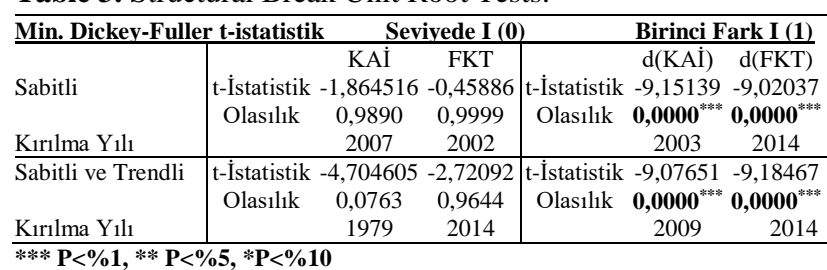

Tablo 4. Uygun gecikme uzunluğu testi.

Table 4. Suitable lag length test.

\begin{tabular}{lllllll}
\hline Lag & \multicolumn{1}{c}{ LogL } & \multicolumn{1}{c}{ LR } & \multicolumn{1}{c}{ FPE } & \multicolumn{1}{c}{ AIC } & \multicolumn{1}{c}{ SC } & \multicolumn{1}{c}{ HQ } \\
\hline 0 & $-421,0326$ & NA & 1202843 & 19,67594 & 19,75785 & 19,70614 \\
1 & $-326,3509$ & $\mathbf{1 7 6 , 1 5 2 0 *}^{*}$ & $\mathbf{1 7 7 2 7 , 6 8 *}^{*}$ & $\mathbf{1 5 , 4 5 8 1 8 *}$ & $\mathbf{1 5 , 7 0 3 9 3 *}^{*}$ & $\mathbf{1 5 , 5 4 8 8 1 *}^{*}$ \\
2 & $-322,9195$ & 6,064928 & 18232,94 & 15,48463 & 15,89421 & 15,63567 \\
3 & $-318,5461$ & 7,322797 & 17986,06 & 15,46726 & 16,04068 & 15,67872 \\
4 & $-315,4003$ & 4,974728 & 18841,08 & 15,50699 & 16,24424 & 15,77887 \\
\hline
\end{tabular}

Tablo 5. Eşbütünleşme Analizi.

Table 5. Cointegration Analysis.

\begin{tabular}{|c|c|c|c|c|}
\hline \multicolumn{5}{|c|}{ İz Test İstatistiği (Trace) } \\
\hline & & & $\% 5$ Kritik & \\
\hline Hipotez & Özdeğer & İz İstatistiği & Değer & Olasilik** \\
\hline$r=0$ & 0,324375 & 22,43705 & 15,49471 & 0,0038 \\
\hline$r>1$ & 0,101010 & 4,791761 & 3,841466 & 0,0286 \\
\hline \multicolumn{5}{|c|}{ Maksimum Özdeğer Test İstatistiği (Maximum Eigenvalue) } \\
\hline & & & $\% 5$ Kritik & \\
\hline Hipotez & Özdeğer & İz İstatistiği & Değer & Olasılık** \\
\hline$r=0$ & 0,324375 & 17,64529 & 14,26460 & 0,0141 \\
\hline$r>1$ & 0,101010 & 4,791761 & 3,841466 & 0,0286 \\
\hline
\end{tabular}

Vektör Hata Düzeltme Modeli (VECM) Uygulaması: Değişkenler arasındaki uzun dönem dengesi ile kısa dönem dinamikleri arasındaki ayırımı saptayabilmek için vektör hata düzeltme modeli (VECM) uygulanmaktadır (Kocabıyık, 2016). Değişkenler arasında bulduğumuz eşbütünleşme ilişkisinin, değişkenlerin kısa 
dönemdeki dengeden sapma eğilimlerinin belirlenmesi için vektör hata düzeltme modeli de uygulanmıştır (Tablo 6).

Tablo 6. Hata düzeltme modeli.

Table 6. Error correction model.

\begin{tabular}{|c|c|c|}
\hline Koentegrasyon Denklemi & CointEq1 & \\
\hline KAI(-1) & 1,000000 & \\
\hline $\operatorname{FKT}(-1)$ & $-8,74 \mathrm{E}-05$ & \\
\hline & $(1,1 \mathrm{E}-05)$ & \\
\hline & {$[-7,75944]$} & \\
\hline Hata Düzeltme & D(KAI) & D(FKT) \\
\hline \multirow[t]{3}{*}{ CointEq1 } & $-0,023318$ & $-926,3261$ \\
\hline & $(0,00918)$ & $(212,416)$ \\
\hline & {$[-2,53893]$} & {$[-4,36090]$} \\
\hline \multirow{3}{*}{$\mathrm{D}(\mathrm{KAI}(-1))$} & $-0,295605$ & 140,3120 \\
\hline & $(0,27141)$ & $(6277,32)$ \\
\hline & {$[-1,08915]$} & {$[0,02235]$} \\
\hline \multirow[t]{3}{*}{$\mathrm{D}(\mathrm{FKT}(-1))$} & $-1,74 \mathrm{E}-06$ & $-0,258195$ \\
\hline & $(1,2 \mathrm{E}-05)$ & $(0,28258)$ \\
\hline & {$[-0,14245]$} & {$[-0,91371]$} \\
\hline $\mathrm{R}^{2}$ & 0,111921 & 0,115089 \\
\hline F-istatistik & 2,646549 & 2,731205 \\
\hline AIC & $-1,661501$ & 18,43615 \\
\hline $\mathrm{SC}$ & $-1,541057$ & 18,55660 \\
\hline
\end{tabular}

Uygulamada, hata düzeltme parametresinin istatistiksel olarak anlamlı ve negatif olması beklenir (Ar1 \& Yıldız, 2017). Hata düzeltme modeli test sonuçlarına göre, hata düzeltme katsayıs $-0,023318$ ve 0,00918 olasılık değeri ile anlamlı olduğundan hata düzeltme mekanizması çalışmaktadır. Buna göre bir dönemde meydana gelen dengesizlik sonraki dönemde düzelebilecektir. Dolayısıyla değişkenler için kurulan modelde uzun dönem ilişkisi tutarlıdır ve bu durum, dengeden sapma olması halinde uzun dönemde tekrar dengeye geleceğini göstermektedir.

Tanısal Sinama Test Uygulamast: Tablo 7'de ki sonuçlar \%5 anlamlılık düzeyinde bir otokorelasyon probleminin olmadığını, aynı şekilde tablo 8 ' de ise olasılık değerinin \% 5 'in üzerinde olması, bu değişkenler arasında değişen varyans sorununun olmadığını göstermektedir.

Tablo 7. Otokorelasyon testi.

Table 7. Autocorrelation test.

\begin{tabular}{lllllll}
\hline \multicolumn{7}{c}{ Null hypothesis: No serial correlation at lag h } \\
\hline Lag & LRE* stat & df & Prob. & Rao F-stat & df & Prob. \\
1 & 4,391559 & 4 & 0,3556 & 1,115129 & $(4,76,0)$ & $\mathbf{0 , 3 5 5 7}$ \\
2 & 2,793124 & 4 & 0,5930 & 0,701865 & $(4,76,0)$ & $\mathbf{0 , 5 9 3 1}$ \\
\hline \multicolumn{7}{c}{ Null hypothesis: No serial correlation at lags 1 to h } \\
\hline Lag & LRE* stat & df & Prob. & Rao F-stat & df & Prob. \\
1 & 4,391559 & 4 & 0,3556 & 1,115129 & $(4,76,0)$ & $\mathbf{0 , 3 5 5 7}$ \\
2 & 6,384935 & 8 & 0,6042 & 0,799752 & $(8,72,0)$ & $\mathbf{0 , 6 0 4 7}$ \\
\hline
\end{tabular}

Tablo 8. Değişen varyans analizi.

Table 8. Variable analysis of variance.

\begin{tabular}{lcc}
\hline Joint test: & & \\
\hline Chi-sq & df & Prob. \\
19,26218 & 18 & $\mathbf{0 , 3 7 5 8}$ \\
\hline
\end{tabular}

\section{SONUÇ}

Sonuç olarak, Türkiye'nin 1971-2017 dönemine ait verilerin kullanıldığı bu çalışmada Türkiye karbon ayak izi (KAI) ve fosil kaynak tüketiminin (FKT) aralarındaki ilişki literatür özeti ile anlatılmış ve ardından bu ilişkinin istatistiksel olarak anlamlılığı Johansen Eşbütünleşme testi ile ortaya konmuştur. Eşbütünleşme sonuçlarının olasılık değerlerinin anlamlı çıkması ile, değişkenler arasında uzun dönemli bir ilişkininin olduğunu doğrulamıştır. Vektör hata düzeltme modelinde bulunan sonuçlar ile de değişkenler arasında oluşabilecek bir etkinin uzun dönemde dengeye girebileceğini göstermiştir. Uluslararası İklim Araştırma Merkezi'nde emisyon analizi üzerinde çalışan bir araştırmacı olan Glen Peters, 'Hükümetlerin sadece yenilenebilir enerjiyi teşvik etmelerinin yeterli olmadığını aynı zamanda fosil yakıtları ortadan kaldırmaya odaklanan daha fazla politikaya ihtiyacımız olduğunu' söylemektedir. $\mathrm{Bu}$ kapsamda sürdürülebilir kalkınma hedeflerinin önemli konularından biri olan iklim değişikliği ile mücadele kapsamında temiz ve çevre dostu kaynak kullanımının artırılması ve FKT'nin azaltılması ile bu hedeflere ulaşılabileceği ortadadır. Küresel olarak artan enerji talebinin fosil yakıtlardan karşılandığı günümüzde, bu kaynakların neden olduğu problemler tüm dünyada olduğu gibi ülkemiz de görülmektedir. Artan sera gazı emisyonlarının çevre kalitesi ve insan sağlığına olan etkilerinin göstergelerinden biri olan KAI'nde yaşanan artış bunun en ciddi kanıtıdır. Elde edilen sonuçlar KAI'de meydana gelen artışın sebeplerinden biri olan FKT'nin etkisini göstermektedir.

\section{KAYNAKLAR}

Akel, V. (2015). Kırılgan Beşli Ülkelerinin Hisse Senedi Piyasaları Arasındaki Eşbütünleşme Analizi. Uluslararası Yönetim Iktisat ve İşletme Dergisi, 11, 24. DOI: 10.17130/ijmeb.2015.11.24.719

Arbex, M. \& Batu, M. (2020). What if people value nature? Climate changeand welfare costs. Resource and Energy Economics, 61, 101176. DOI: 10.1016/j.reseneeco.2020.101176

Arı, E. \& Yıldız, A. (2017). Eşbütünleşme Analizi İle Genç İşsizliği Etkileyen Değişkenlerin Araştırılması. Alphanumeric journal, 5, 310-316. DOI: 10.17093/alphanumeric.349358

Bilim ve Teknik. (2016). Fosil Yakıtlar. https://bilimteknik.tubitak.gov.tr/content/fosilyakitlar. (22.12.2020).

Buono, D.D. (2021). Can biostimulants be used to mitigate the effect of anthropogenic climate change on agriculture? It is time to respond. Science of the Total Environment, 751, 141763. DOI: 10.1016/j.scitotenv.2020.141763

Cai, M., Murtazashvili, I., Murtazashvili, J.B. \& Salahodjaev, R. (2020). Patience and climate change mitigation: Global evidence. Environmental Research, 186, 109552. DOI: 10.1016/j.envres.2020.109552 
Coelho, S., Rafael, S., Lopes, D., Miranda, A.I. \& Ferreira, J. (2020). How changing climate may influence air pollution control strategies for 2030?. Science of the Total Environment, 9697, 37442-8. DOI: 10.1016/j.envres.2020.109552

Çiftci, N. (2014). Türkiye'de Cari Açık, Reel Döviz Kuru ve Ekonomik Büyüme Arasındaki İlişkiler: Eş Bütünleşme Analizi. Anadolu Üniversitesi Sosyal Bilimler Dergisi. 14, 129-142. DOI: 10.18037/ausbd.12816

Dickey, D.A. \& Fuller, W.A. (1997). Distribution of the estimators for autoregressive time series with a unit root. J. Am. Stat. Assoc, 74, 427-431. DOI: $10.2307 / 2286348$

Engle, R.F. \& Granger, C.W.J. (1987). Cointegration and error correction: Representation.,estimation and testing. Econometrica, 55, 251-76. DOI: $10.2307 / 1913236$

GFP. (2020a). Global Footprint (GFP). https://data.footprintnetwork.org. (21.12.2020).

GFP. (2020b). Global Footprint (GFP). Turkey Ecological Footprint Data. https://data.footprintnetwork.org. (21.12.2020).

Haines, A. \& Ebi, K. (2019). The Imperative for Climate Action to Protect Health. The new england journal of medicine, 80, 263-73. DOI: 10.1056/NEJMra1807873

Haines, A., Kovats, RS., Lendrum, D.C. \& Corvalan, C. (2005). Climate change and human health: Impacts, vulnerability and public health. Public Health, 120, 585-596. DOI: 10.1016/j.puhe.2006.01.002.

Hiatt, R.A. \& Beyeler, N. (2020). Cancer and climate change. Lancet Oncol, 21, 519-527. DOI: 10.1016/S14702045(20)30448-4.

Hrabok, M., Delorme, A. \& Agyapong, V.I.O. (2020). Threats to Mental Health and Well-Being Associated with Climate Change. Journal of Anxiety Disorders, 76, 102295. DOI: 10.1016/j.janxdis.2020.102295.

Hughes, J., Heays, K.J., Olesson, E. \& Bell, R. (2020). Impacts and implications of climate change on wastewater systems: A New Zealand perspective. Climate Risk Management, S2212-0963(20), 30052-8. DOI: 10.1016/j.crm.2020.100262

IEA (International Energy Agency). (2016). Energy Policies of IEA Countries Turkey.

IEA. (2020). International Energy Agency. Explore energy data by category: World Total final consumption. https://www.iea.org.data-and-statisticsdata-tables country. (21.12.2020).

IEA. (2020a). International Energy Agency (IEA). Explore energy data by category: Turkey Total final consumption. https://www.iea.org.data-andstatistics.data-tablescountry. 21.12.2020).

IEA. (2020b). International Energy Agency (IEA). Total energy supply (TES) by source, Turkey 19902018. https://www.iea.org.data-and statistics country. (21.12.2020).

IPCC. (2014). Intergovernmental Panel on Climate Change (IPCC), Climate Change 2014 Mitigation of Climate Change. Working Group III Contribution to the Fifth Assessment Report of the Intergovernmental Panel on Climate Change.

IPCC. (2019). Intergovernmental Panel on Climate Change (IPCC), Global warming of $1,5^{\circ} \mathrm{C}$.

Johansen, S. (1988). Statistical analysis of cointegration vectors. Journal of Economics Dynamic and Control, 12 (2-3), 231-254. DOI: 10.1016/01651889(88)90041-3

Jóhannesson, E.S., Heinonen, J. \& Davíosdóttir, B. (2020). Data accuracy in Ecological Footprint's carbon footprint. Ecological Indicators, 111, 105983. DOI: $10.1016 /$ j.ecolind.2019.105983

Khan, I., Hou, F. \& Le, H.P. (2021). The impact of natural resources, energy consumption, and population growth on environmental quality: Fresh evidence from the United States of America. Science of the Total Environment, 754, 142222. DOI: 10.1016/j.scitotenv.2020.142222

Kober, T., Schiffer, H.W., Densing, M. \& Panos, E. (2020). Global energy perspectives to 2060 WEC's World Energy Scenarios 2019. Energy Strategy Reviews, 31, 100523. DOI: 10.1016/j.esr.2020.100523

Kocabıyık, T. (2016). Johansen Eşbütünleşme Testinde Karar Aşamalarının Analizi. Süleyman Demirel Üniversitesi Sosyal Bilimler Enstitüsü Dergisi, CIEP Özel Sayısı.

Koomson, D., Vollum, K.T.S. \& Raha, D. (2020). Characterising the vulnerability of fishing households to climate and environmental change: Insights from Ghana. Marine Policy, 120, 104142. DOI: 10.1016/j.marpol.2020.104142

Kowalski, M.F., Rovenskaya. E., Krausmann, F., Pallua, I. \& Neill, J.R.M. (2019). Energy transitions and social revolutions. Technological Forecasting \& Social Change, 138, 69-77. DOI: 10.1016/j.techfore.2018.08.010

Lidicker, W.Z. (2020). A Scientist's Warning to humanity on human population growth. Global Ecology and Conservation, 24, $01232 . \quad$ DOI: 10.1016/j.gecco.2020.e01232

Martins, F., Felgueiras, C. \& Smitková, M. (2018). Fossil fuel energy consumption in European 
countries. Energy Procedia, 153, 107-111. DOI:

10.1016/j.egypro.2018.10.050

MGM. (2017). Meteoroloji Genel Müdürlüğü: İklim Değişikliği ve Mevcut Durum. https://mgm.gov.tr/iklim/iklim-degisikligi.aspx. (22.12.2020).

Monserrate, A.Z., Ruano, M.A., Candelario, V.O. \& Loor, D.A.S. (2020). Global ecological footprint and spatial dependence between countries. Journal of Environmental Management, 272, 111069. DOI: 10.1016/j.jenvman.2020.111069

Nicholas, P.K., Breakey, S., McKinnon, S., Eddy, E.Z., Fanuele, J. \& Starodub, R. (2020). A climate: a tool for assessment of Climate-change-related health. Emergency Nurses Association, 20, 1-11. DOI: $10.1016 /$ j.jen.2020.10.002

Nicholas, P.K., Breakey, S., Tagliareni, E., Simmonds, K. \& Sabo, K.K. (2020). Climate Change and Population Health: Incorporating Stages of Nursing's Political Development. Nursing Outlook, $\quad 69(1), \quad 1-9 . \quad$ DOI: 10.1016/j.outlook.2020.08.001

Özgül, S., Koçar, G. \& Eryaşar, A. (2020). The progress, challenges, and opportunities of renewable energy cooperatives in Turkey. Energy for Sustainable Development, 59, 107-119. DOI: 10.1016/j.esd.2020.09.005

Paramati, S.R., Apergis, N. \& Ummalla, M, (2017). Dynamics of renewable energy consumption and economic activities across the agriculture, industry, and service sectors: evidence in the perspective of sustainable development. Environmental Science and Pollution Research, 25, 1375-1387. DOI: 10.1007/s11356-017-05527

Petrov, O., Bi, X. \& Lau, A. (2017). Impact assessment of biomass-based district heating systems in densely populated communities. Part II: Would the replacement of fossil fuels improve ambient air quality and human health?. Atmospheric Environment, 161, 191-199. DOI: 10.1016/j.atmosenv.2017.05.001

Phillips, P.C.B. \& Perron, P. (1988). Testing for a Unit Root in Time Series Regression. Biometrika (Printed Gt. Britain), 75, 335-346. DOI: $10.2307 / 2336182$

Qayyum, U., Anjum, S. \& Sabir, S. (2021). Armed conflict, militarization and ecological footprint: Empirical evidence from South Asia. Journal of Cleaner Production, 281, 125299. DOI: 10.1016/j.jclepro.2020.125299

Qin, P., Xu, H., Liu, M., Xiao, C., Forrest, K.E., Samuelsen, S. \& Tarroja, B. (2020). Assessing concurrent effects of climate change on hydropower supply, electricity demand, and greenhouse gas emissions in the Upper Yangtze River Basin of China. Applied Energy, 279, 115694. DOI: 10.1016/j.apenergy.2020.115694

Rauf, A., Liu, X., Amin, W., Rehman, O.U., Li, J., Ahmad, F. \& Bekun, F.V. (2020). Does sustainable growth, energy consumption and environment challenges matter for Belt and Road Initiative feat? A novel empirical investigation. Journal of Cleaner Production, 262, 121344. DOI: 10.1016/j.jclepro.2020.121344

Rees, W.E. (1992). Ecological Footprints and appropriated carrying capacity: what urban economics leaves out. Environment and Urbanization, 4(2), 121130. DOI: $10.1177 / 2455747117699722$

Salvia, A.L., Filho, W.L., Brandli, L.L. \& Griebeler, J.S. (2019). Assessing research trends related to Sustainable Development Goals: local and global issues. Journal of Cleaner Production, 208, 841849. DOI: $10.1016 /$ j.jclepro.2018.09.242

Schachtel, A., Dyer, J.A. \& Boos, M.D. (2020). Climate change and pediatric skin health. International Journal of Women's Dermatology, 1, 85-90. DOI: 10.1016/j.ijwd.2020.07.006

Sintayehu, D.W., Dalle, G. \& Bobasa, A.F. (2020). Impacts of climate change on current and future invasion of Prosopis juliflora in Ethiopia: environmental and socio-economic implications. Heliyon, $\quad$ 6, e04596. DOI: 10.1016/j.heliyon.2020.e04596

TUİK. (2020). Türkiye İstatistik Kurumu; Sera Gazı Emisyon İstatistikleri, 1990-2018. https://tuikweb.tuik.gov.tr/PreHaberBultenleri.do ?id=33624. (21.12.2020).

UN. (1987). United Nations (UN), Report of the World Commission on Environment and Development: Our Common Future.

UN. (1992). United Nations (UN) Framework Convention on Climate Change.

UN. (2015). United Nations (UN), Transforming our World: The 2030 Agenda for Sustainable Development.

UN. (2019). United Nations (UN), 2019 Revision of World Population Prospects.

WWF. (2012). World Wide Fund for Nature (WWF), Türkiye'nin Ekolojik Ayak İzi Raporu. 